\title{
28 Research Square \\ Prognostic value of estimated plasma volume status in patients with sepsis
}

\section{Kyung Hoon Kim}

Catholic University of Korea School of Medicine

Hyeong Jun Cho

Catholic University of Korea School of Medicine

Seok Chan Kim

Catholic University of Korea School of Medicine

Jongmin Lee ( $\nabla$ dibs03@gmail.com )

Catholic University of Korea School of Medicine https://orcid.org/0000-0002-0165-5856

Research

Keywords: sepsis, estimated plasma volume status, prognostic value

Posted Date: May 6th, 2021

DOI: https://doi.org/10.21203/rs.3.rs-475018/v1

License: (c) (1) This work is licensed under a Creative Commons Attribution 4.0 International License. Read Full License 


\section{Abstract}

Background: Sepsis is associated with endothelial dysfunction and alteration of capillary permeability. The objective of this study was to evaluate the prognostic value of estimated plasma volume status (ePVS) in patients with sepsis or septic shock who were admitted to intensive care unit (ICU).

Methods: In this single-center, prospective observational study, 100 patients with sepsis or septic shock who were admitted ICU were enrolled. The primary outcome was in-hospital mortality and multivariable logistic regression analysis was used to adjust for confounding factors.

Results: The in-hospital mortality was $47 \%$. The mean ePVS in patients who died was higher than in those who survived $(7.7 \pm 2.1 \mathrm{dL} / \mathrm{g}$ vs. $6.6 \pm 1.6 \mathrm{dL} / \mathrm{g}, P=0.003)$. To evaluate the utility of ePVS in predicting in-hospital mortality, a receiver operating characteristic curve was produced. Sensitivity and specificity were optimal at a cut-off point of $7.09 \mathrm{dL} / \mathrm{g}$, with an area under the curve of 0.655 . In the multivariate analysis, higher ePVS was significantly associated with higher in-hospital mortality (adjusted odds ratio, 1.39; $95 \%$ confidence interval, $1.04-1.85, P=0.028)$. The Kaplan-Meier curve showed that an ePVS value above 7.09 is associated with an increased risk of in-hospital mortality compared to the rest of the population $(P=0.004)$.

Conclusions: The ePVS provided additional prognostic value in patients with sepsis or septic shock who were admitted in the ICU.

\section{Introduction}

Sepsis is a life-threatening organ dysfunction caused by a dysregulated host response to infection [1]. It is associated with endothelial cell dysfunction leading to disruption in normal regulation of transcapillary fluid exchange and interstitial edema [2, 3]. Therefore, it is important to assess the volume status of patients for its management. To evaluate the volume status and fluid responsiveness of patients with sepsis, measurement of stroke volume variation (SSV) or pulse pressure variation (PPV) is mainly used $[4,5]$. However, using these techniques is intricate and time-consuming. Therefore, a simple method is needed.

Plasma volume is associated with the regulation between interstitial and intravascular spaces and can be used as a marker for volume overload [6]. Recently, Duarte et al. proposed to use a simple formula based on hemoglobin and hematocrit to estimate the plasma volume in patients with heart failure [7]. Previous studies have reported that high estimated plasma volume status (ePVS) was related to poor prognosis of these patients $[8,9]$. Furthermore, studies have previously shown that ePVS value at emergency department admission correlated with the risk of death in patients with fever or dyspnea $[10,11]$. However, few studies have evaluated its prognostic power in patients with sepsis or septic shock admitted in intensive care unit (ICU). 
Therefore, we conducted a prospective observational study to assess the prognostic power of ePVS in critically ill patients with sepsis who required ICU admission.

\section{Methods}

\section{Study population}

This is a monocentric prospective observational study conducted at the ICU of the Seoul St. Mary's Hospital, Korea (460,000 visits per year, 1,369 beds, and 20 medical ICU beds) from March 2019 to June 2020. During the period, blood samples were collected from patients with sepsis on the day of ICU admission. Sepsis was diagnosed according to the third international consensus definitions for sepsis and septic shock (Sepsis-3). Patients with a history of bleeding or transfusion within 3 days prior to ICU admission were excluded. On the day of ICU admission (day 1), Sequential Organ Failure Assessment (SOFA) and Simplified Acute Physiology Score 3 (SAPS 3) scores were used as indicators of sepsis severity. We collected comorbidity data of the participants and used them to calculate the Charlson comorbidity score index [12]. Variables shown in Table 1 were measured and recorded on day 1. 
Table 1

Comparison of baseline characteristics of the study population at ICU admission ( $N=100)$.

\begin{tabular}{|c|c|c|c|c|}
\hline & $\begin{array}{l}\text { Total } \\
(n=100)\end{array}$ & $\begin{array}{l}\text { Survivor } \\
(n=53)\end{array}$ & $\begin{array}{l}\text { Non-survivor } \\
(n=47)\end{array}$ & $\begin{array}{l}P \\
\text { value }\end{array}$ \\
\hline Age, years & $69(56.5-80.0)$ & $71.0(61.0-79.0)$ & $\begin{array}{l}64.0(51.5- \\
80.0)\end{array}$ & 0.335 \\
\hline Sex, male (\%) & $54(54.0)$ & $31(58.5)$ & $23(48.9)$ & 0.450 \\
\hline Body weight (kg) & $58.0(51.0-66.8)$ & $59.4(52.0-66.6)$ & $\begin{array}{l}57.0(50.5- \\
66.0)\end{array}$ & 0.429 \\
\hline Septic shock, n (\%) & $60(60.0)$ & $30(56.6)$ & $30(63.8)$ & 0.595 \\
\hline SAPS3 score & $78.3 \pm 14.1$ & $72.2 \pm 12.0$ & $85.1 \pm 13.2$ & $<.001$ \\
\hline SOFA score & $9.0(7.0-12.0)$ & $8.0(7.0-11.0)$ & $11.0(8.0-14.0)$ & $\begin{array}{l}< \\
0.001\end{array}$ \\
\hline Charlson comorbidity index & $5.0(4.0-7.0)$ & $6.0(4.0-8.0)$ & $5.0(4.0-7.0)$ & 0.228 \\
\hline $\begin{array}{l}\text { Use of vasopressors at day } 1, n \\
\text { (\%) }\end{array}$ & $74(74.0)$ & $37(69.8)$ & $37(78.7)$ & 0.883 \\
\hline $\begin{array}{l}\text { Use of inotropics at day } 1, \mathrm{n} \\
(\%)\end{array}$ & $2(2.0)$ & $0(0.0)$ & $2(4.3)$ & 0.423 \\
\hline Use of IMV at day 1, n (\%) & $44(44.0)$ & $16(30.2)$ & $28(59.6)$ & 0.006 \\
\hline Hemoglobin (g/dL) & $10.3 \pm 2.0$ & $10.5(9.2-11.7)$ & $9.2(8.5-10.8)$ & 0.007 \\
\hline Hematocrit (\%) & $29.9(26.2-35.0)$ & $31.8(27.6-35.4)$ & $\begin{array}{l}28.0(25.0- \\
33.1)\end{array}$ & 0.012 \\
\hline ePVS (dL/g) & $7.1 \pm 1.9$ & $6.6 \pm 1.6$ & $7.7 \pm 2.1$ & 0.003 \\
\hline Lactic acid at day 1 (mmol/L) & $3.0(1.5-6.5)$ & $2.4(1.3-4.0)$ & $4.0(1.8-7.7)$ & 0.040 \\
\hline Procalcitonin at day $1(\mathrm{ng} / \mathrm{mL})$ & $10.6(2.2-52.0)$ & $10.6(1.5-40.2)$ & $11.3(2.8-54.1)$ & 0.912 \\
\hline WBC at day $1\left(10^{9} / \mathrm{L}\right)$ & $10.1(3.0-16.8)$ & $10.2(4.3-17.5)$ & $8.6(1.1-16.1)$ & 0.334 \\
\hline ANC at day $1\left(10^{9} / \mathrm{L}\right)$ & $7.8(1.7-14.5)$ & $7.9(2.5-15.2)$ & $6.6(0.5-13.4)$ & 0.224 \\
\hline Platelets at day $1\left(10^{9} / \mathrm{L}\right)$ & $\begin{array}{l}104.0(35.0- \\
206.0)\end{array}$ & $\begin{array}{l}168.0(47.0- \\
234.0)\end{array}$ & $\begin{array}{l}64.0(30.0- \\
127.0)\end{array}$ & 0.004 \\
\hline CRP at day $1(\mathrm{mg} / \mathrm{dL})$ & $16.3(9.1-25.9)$ & $16.7(9.1-24.1)$ & $16.1(9.3-27.2)$ & 0.617 \\
\hline
\end{tabular}

SAPS3, Simplified Acute Physiology Score 3; SOFA, sequential organ failure assessment; IMV, invasive mechanical ventilation; ePVS, estimated plasma volume status; WBC, white blood cells; ANC, absolute neutrophil count; CRP, C-reactive protein; BUN, blood urea nitrogen; GFR, glomerular filtration rate; SBP, systolic blood pressure; DBP, diastolic blood pressure; HR, heart rates; RR, respiratory rates. 


\begin{tabular}{|c|c|c|c|c|}
\hline & $\begin{array}{l}\text { Total } \\
(n=100)\end{array}$ & $\begin{array}{l}\text { Survivor } \\
(n=53)\end{array}$ & $\begin{array}{l}\text { Non-survivor } \\
(n=47)\end{array}$ & $\begin{array}{l}P \\
\text { value }\end{array}$ \\
\hline BUN at day $1(\mathrm{mg} / \mathrm{dL})$ & $35.6(24.6-52.5)$ & $35.2(23.2-51.2)$ & $\begin{array}{l}36.1(24.7- \\
55.3)\end{array}$ & 0.377 \\
\hline Creatinine at day 1 (mg/dL) & $1.6(0.9-2.4)$ & $1.6(0.9-2.6)$ & $1.6(0.8-2.4)$ & 0.738 \\
\hline GFR at day $1\left(\mathrm{ml} / \mathrm{min} / 1.73 \mathrm{~m}^{2}\right)$ & $38.1(21.8-71.8)$ & $37.7(22.4-68.3)$ & $\begin{array}{l}40.9(22.1- \\
80.8)\end{array}$ & 0.691 \\
\hline SBP at day $1(\mathrm{mmHg})$ & $80.0(70.0-90.0)$ & $78.0(70.0-88.0)$ & $\begin{array}{l}81.0(71.5- \\
90.0)\end{array}$ & 0.597 \\
\hline DBP at day $1(\mathrm{mmHg})$ & $47.5(40.0-55.5)$ & $47.7 \pm 11.3$ & $48.9 \pm 13.0$ & 0.602 \\
\hline HR at day 1 (beats per min) & $131.8 \pm 26.6$ & $124.4 \pm 25.2$ & $140.0 \pm 25.9$ & 0.003 \\
\hline RR at day 1 (rates per min) & $31.0(24.0-35.5)$ & $28.0(23.0-34.0)$ & $\begin{array}{l}33.0(26.5- \\
38.5)\end{array}$ & 0.019 \\
\hline \multicolumn{5}{|c|}{$\begin{array}{l}\text { SAPS3, Simplified Acute Physiology Score 3; SOFA, sequential organ failure assessment; IMV, } \\
\text { invasive mechanical ventilation; ePVS, estimated plasma volume status; WBC, white blood cells; ANC, } \\
\text { absolute neutrophil count; CRP, C-reactive protein; BUN, blood urea nitrogen; GFR, glomerular filtration } \\
\text { rate; SBP, systolic blood pressure; DBP, diastolic blood pressure; HR, heart rates; RR, respiratory rates. }\end{array}$} \\
\hline
\end{tabular}

This study was conducted in accordance with the relevant legislation and approved by the Ethics Committee of Seoul St. Mary's Hospital (KC18DESI0739) and complied with the Declaration of Helsinki and Good Clinical Practice Guidelines. Informed consent was obtained from all participants included in the study.

\section{ePVS measurement}

Blood samples were collected at ICU admission and complete blood count (CBC) was analyzed using Sysmex analyzer (Sysmex XN-9000, Sysmex Co, Kobe, Japan). The ePVS value was calculated using the hematocrit and hemoglobin values from the $\mathrm{CBC}$ performed upon arrival at the ICU, using the following formula [7]:

$$
=\operatorname{ePVS}\left(\frac{\mathrm{dL}}{\mathrm{g}}\right)=\frac{100-\mathrm{Ht}(\%)}{\mathrm{Hb}(\mathrm{g} / \mathrm{dl})}
$$

\section{Statistical analyses}

All statistical analyses were performed using the R 4.0.2 version (R Foundation, Vienna, Austria). All results were reported as means \pm standard deviations for normally distributed continuous variables and as medians and interquartile ranges (IQRs) for non-normally distributed continuous data. Categorical data were described as numbers and percentages. Patient characteristics were compared using the chi- 
square test or Fisher's exact test for categorical variables, and independent samples $t$-tests for continuous variables. Multivariate analysis was performed to investigate associations between patient characteristics and in-hospital mortality. Odds ratios (ORs) and the corresponding 95\% confidence intervals (Cls) were computed. Goodness-of-fit was computed to assess the relevance of the logistic regression model. Receiver operating characteristic (ROC) curves were used to evaluate the ability of ePVS for predicting in-hospital mortality. Probabilities of in-hospital survival for each group were estimated using the Kaplan-Meier method and compared using the log rank test. All tests were two-sided, and $P$ values $<0.05$ were considered statistically significant.

\section{Results}

\section{Baseline Characteristics}

A total of 100 patients (54 men and 46 women) were included in this study, and 47 (47.0\%) patients died in-hospital. All patients met the criteria for sepsis or septic shock according to the Sepsis-3 criteria. Baseline characteristics of the patients are shown in Table 1. The median age of the patients was 69.0 years (IQR, 56.5-80.0), and median body weight was $58.0 \mathrm{~kg}$ (IQR, 51.0-66.0). Septic shock was diagnosed in $60(60.0 \%)$ patients. The mean initial SAPS 3 and median SOFA score on day 1 were $78.3 \pm$ 14.1 and 9.0 (IQR, 7.0-12.0), respectively, and both scores were significantly higher in non-survivors than those in survivors (both, $P<0.001$ ). The median hemoglobin and hematocrit values were significantly lower in non-survivors than those in survivors ( $P=0.007$ for hemoglobin; $P=0.012$ for hematocrit). Among the cases, 74 (74.0\%) needed vasopressor support and 44 (44.0\%) had hypoxemia-requiring invasive ventilation. The mean value of ePVS was $7.1 \pm 1.9 \mathrm{dL} / \mathrm{g}$ and significantly higher in non-survivors (7.7 \pm 2.1 vs. $6.6 \pm 1.6, P=0.003$ ).

\section{In-hospital Mortality Prediction Performance of ePVS}

ROC curves were generated to compare the ePVS, SOFA, and SAPS for predicting in-hospital mortality in patients with sepsis or septic shock who required ICU admission (Fig. 1). In all patients, ePVS showed an area under the curve (AUC) of $0.655(95 \% \mathrm{Cl}, 0.553-0.747)$, with $61.7 \%$ sensitivity and $67.9 \%$ specificity, at cutoff point $\geq 7.09 \mathrm{dL} / \mathrm{g}$. While SAPS3 showed an AUC of $0.768(95 \% \mathrm{Cl}, 0.673-0.847)$ with $72.3 \%$ sensitivity and $79.3 \%$ specificity, and SOFA showed an AUC of $0.724(95 \% \mathrm{Cl}, 0.625-0.809)$ with $48.9 \%$ sensitivity and $72.3 \%$ specificity, but the AUC among the three scores was not significantly different $(P=$ $0.365)$.

Table 2 lists the patient outcomes according to ePVS values. Patients with ePVS above $7.09 \mathrm{dL} / \mathrm{g}$ had a significantly higher rate of ICU mortality (53.2\% vs. $30.2 \%, P=0.033)$, and in-hospital mortality as compared with those with ePVS below the value $(61.7 \%$ vs. $34.0 \%, P=0.010)$. Patients with ePVS above $7.09 \mathrm{dL} / \mathrm{g}$ had a significantly higher rate of use of renal replacement therapy (RRT) during ICU stay (44.7\% vs. $20.8 \%, P=0.019$ ). 
Table 2

Comparison of baseline characteristics and outcomes according to cut-off ePVS value

\begin{tabular}{|c|c|c|c|}
\hline & $\begin{array}{l}\text { ePVS }<7.09 \mathrm{dL} / \mathrm{g} \\
(\mathrm{N}=53)\end{array}$ & $\begin{array}{l}\text { ePVS } \geq 7.09 \mathrm{dL} / \mathrm{g} \\
(\mathrm{N}=47)\end{array}$ & $P$ value \\
\hline Age, years & $71.0(62.0-82.0)$ & $63.0(51.0-76.5)$ & 0.011 \\
\hline Sex, male (\%) & $33(62.3)$ & $21(44.7)$ & 0.119 \\
\hline Septic shock, n (\%) & $32(60.4)$ & $28(59.6)$ & 1.000 \\
\hline SAPS3 score & $74.6 \pm 13.7$ & $82.4 \pm 13.5$ & 0.005 \\
\hline SOFA score & $9.0(7.0-11.0)$ & $9.0(8.0-13.0)$ & 0.143 \\
\hline SBP at day $1(\mathrm{mmHg})$ & $81.0(70.0-87.0)$ & $80.0(70.5-90.0)$ & 0.507 \\
\hline DBP at day $1(\mathrm{mmHg})$ & $47.0(41.0-55.0)$ & $49.0(40.0-56.0)$ & 0.844 \\
\hline HR at day 1 (beats per min) & $128.9 \pm 28.3$ & $135.0 \pm 24.4$ & 0.250 \\
\hline RR at day 1 (rates per min) & $28.0(22.0-35.0)$ & $31.0(26.5-36.5)$ & 0.126 \\
\hline Lactic acid at day 1 (mmol/L) & $3.2(! .4-6.9)$ & $3.0(1.8-5.4)$ & 0.887 \\
\hline Procalcitonin at day $1(\mathrm{ng} / \mathrm{mL})$ & $9.7(1.8-40.2)$ & $12.2(2.9-59.0)$ & 0.342 \\
\hline CRP at day $1(\mathrm{mg} / \mathrm{dL})$ & $16.7(7.8-25.5)$ & $16.1(11.1-25.6)$ & 0.785 \\
\hline BUN at day $1(\mathrm{mg} / \mathrm{dL})$ & $32.9(23.2-45.1)$ & $39.0(26.8-63.9)$ & 0.073 \\
\hline Creatinine at day 1 (mg/dL) & $1.6(0.9-2.3)$ & $1.6(0.8-2.8)$ & 0.983 \\
\hline GFR at day $1\left(\mathrm{ml} / \mathrm{min} / 1.73 \mathrm{~m}^{2}\right)$ & $42.7(23.5-71.2)$ & $35.2(18.7-73.4)$ & 0.777 \\
\hline Use of IMV during ICU stay, n (\%) & $30(56.6)$ & $32(68.1)$ & 0.330 \\
\hline Use of RRT during ICU stay, n (\%) & $11(20.8)$ & $21(44.7)$ & 0.019 \\
\hline Use of ECMO during ICU stay, n (\%) & $1(1.9)$ & $1(2.1)$ & 1.000 \\
\hline ICU mortality, n (\%) & $16(30.2)$ & $25(53.2)$ & 0.033 \\
\hline In-hospital mortality, n (\%) & $18(34.0)$ & $29(61.7)$ & 0.010 \\
\hline \multicolumn{4}{|c|}{$\begin{array}{l}\text { ePVS, estimated plasma volume status; SAPS3, Simplified Acute Physiology Score 3; SOFA, } \\
\text { sequential organ failure assessment; SBP, systolic blood pressure; DBP, diastolic blood pressure; HR, } \\
\text { heart rates; RR, respiratory rates; CRP, C-reactive protein; BUN, blood urea nitrogen; GFR, glomerular } \\
\text { filtration rate; IMV, invasive mechanical ventilation; RRT, renal replacement therapy; ECMO, } \\
\text { extracorporeal membrane oxygenation; ICU, intensive care unit. }\end{array}$} \\
\hline
\end{tabular}

Factors associated with in-hospital mortality in patients with sepsis 
Logistic regression analysis of clinical parameters for evaluating the risk factors associated with hospital mortality in patients with sepsis is shown in Table 3. The increase of $1 \mathrm{dL} / \mathrm{g}$ in ePVS at day 1 was independently associated with in-hospital mortality on univariate analysis (crude $\mathrm{OR}, 1.40 ; 95 \% \mathrm{Cl}, 1.11-$ $1.77 ; P=0.005)$. Other independent risk factors for hospital mortality were higher lactic acid (crude $\mathrm{OR}$, $1.10 ; 95 \% \mathrm{Cl}, 1.01-1.21 ; P=0.038$ ), higher SAPS3 score (crude OR, 1.09; 95\% $\mathrm{Cl}, 1.04-1.13 ; P<0.001$ ), higher SOFA score (crude OR, 1.27; $95 \% \mathrm{Cl}, 1.11-1.45 ; P<0.001$ ), use of mechanical ventilation (MV) (crude OR, 3.41; 95\% Cl, 1.49-7.79, $P=0.004$ ), higher heart rate (crude OR, 1.02; 95\% Cl, 1.01-1.04; $P=$ 0.005 ), higher respiratory rate (crude $\mathrm{OR}, 1.06 ; 95 \% \mathrm{Cl}, 1.01-1.12 ; P=0.017$ ) at day 1 . After adjusting for potential confounding factors, higher ePVS at day 1 remained significantly associated with in-hospital mortality (adjusted OR, 1.39; 95\% Cl, 1.04-1.85; $P=0.028$ ). Higher SAPS score (adjusted OR, $1.06 ; 95 \% \mathrm{Cl}$, 1.01-1.10; $P=0.011$ ), use of MV (adjusted OR, 3.78; 95\% Cl, $1.23-11.61 ; P=0.020$ ) were also independently associated with in-hospital mortality.

Table 3

univariable analysis for in-hospital mortality

\begin{tabular}{|c|c|c|c|c|c|c|}
\hline \multirow[t]{2}{*}{ Variable } & \multicolumn{3}{|c|}{ Univariate analysis } & \multicolumn{3}{|c|}{ Multivariate analys } \\
\hline & $\begin{array}{l}\text { Crude } \\
\text { OR }\end{array}$ & $95 \% \mathrm{Cl}$ & $\begin{array}{l}P \\
\text { value }\end{array}$ & $\begin{array}{l}\text { Adjusted } \\
\text { OR }\end{array}$ & $95 \% \mathrm{Cl}$ & $\begin{array}{l}P \\
\text { value }\end{array}$ \\
\hline Lactic acid at day 1 (+ $1 \mathrm{mmol} / \mathrm{L})$ & 1.10 & $\begin{array}{l}1.01- \\
1.21\end{array}$ & 0.038 & & & \\
\hline SAPS3 score at day 1 & 1.09 & $\begin{array}{l}1.04- \\
1.13\end{array}$ & $<.001$ & 1.06 & $\begin{array}{l}1.01- \\
1.10\end{array}$ & 0.011 \\
\hline SOFA score at day 1 & 1.27 & $\begin{array}{l}1.11- \\
1.45\end{array}$ & $<0.001$ & & & \\
\hline Use of IMV at ICU admission & 3.41 & $\begin{array}{l}1.49- \\
7.79\end{array}$ & 0.004 & 3.78 & $\begin{array}{l}1.23- \\
11.61\end{array}$ & 0.020 \\
\hline Hemoglobin at day $1(+1 \mathrm{~g} / \mathrm{dL})$ & 0.73 & $\begin{array}{l}0.58- \\
0.92\end{array}$ & 0.009 & & & \\
\hline Hematocrit at day $1(+1 \%)$ & 0.91 & $\begin{array}{l}0.85- \\
0.98\end{array}$ & 0.014 & & & \\
\hline ePVS at day $1(+1 \mathrm{dL} / \mathrm{g})$ & 1.40 & $\begin{array}{l}1.11- \\
1.77\end{array}$ & 0.005 & 1.39 & $\begin{array}{l}1.04- \\
1.85\end{array}$ & 0.028 \\
\hline $\begin{array}{l}\text { Heart rate at day } 1(+1 \\
\text { beats/min) }\end{array}$ & 1.02 & $\begin{array}{l}1.01- \\
1.04\end{array}$ & 0.005 & & & \\
\hline $\begin{array}{l}\text { Respiratory rate at day } 1(+1 \\
\text { rates } / \mathrm{min})\end{array}$ & 1.06 & $\begin{array}{l}1.01- \\
1.12\end{array}$ & 0.017 & & & \\
\hline Platelets at day $1\left(+110^{9} / \mathrm{L}\right)$ & 0.99 & $\begin{array}{l}0.99- \\
1.00\end{array}$ & 0.004 & 0.99 & $\begin{array}{l}0.99- \\
1.00\end{array}$ & 0.044 \\
\hline
\end{tabular}


Finally, the Kaplan-Meier survival analysis showed that patients with ePVS value above the cut-off value $(7.09 \mathrm{dL} / \mathrm{g})$ was associated with an increased risk of in-hospital death as compared to the rest of the population (log-rank test $P=0.004$ ) (Fig. 2).

\section{Discussion}

In this prospective observational study of sepsis patients admitted in the ICU, the ePVS was independently associated with in-hospital mortality even after multivariate adjustment for other patient clinical and laboratory conditions. To our knowledge, this result is the first attempt to predict the outcome of sepsis patients admitted in the ICU using this new biological surrogate. Our result suggests that ePVS could be a promising tool to predict the prognosis of patients with sepsis.

Fluid resuscitation is important for stabilizing hemodynamic status and improving tissue oxygenation [13]. However, it is difficult to accurately estimate the required amount of fluid in patients with sepsis. Although there are several methods to calculate the volume status of patients, all have their limitations $[14,15]$. The direct methods using echocardiogram, SSV, or PPV are complex and time-consuming to apply to routine practice of all patient with sepsis. Therefore, a simple and universally available tool for assessment of volume status is needed.

In patients with sepsis, impairment of microcirculation is induced by release of proinflammatory cytokines $[16,17]$. Microcirculatory dysfunction induces maldistribution of microvascular blood flow, and increased endothelial permeability leads fluid leakage from the intravascular space and tissue edema [18-20]. Accumulation of water in tissue leads to tissue hypoxia, and if not corrected, it can induce organ failure and death [21, 22]. It has been suggested that ePVS, which is derived from the Strauss formula using hemoglobin and hematocrit, may reflect plasma volume shifts at the level of interstitial tissue and therefore can be used clinically to estimate the severity of the microcirculatory dysfunction in patients with sepsis and heart failure $[8,10,11,23]$.

Initially, ePVS was developed primarily to predict the prognosis of patients with heart failure (HF). In patients with HF after acute myocardial infarction, higher ePVS was significantly associated with hospitalization or cardiovascular death [7]. Furthermore, decrease in ePVS was related with decongestion due to effective treatment and associated with better cardiovascular outcome [7-9]. Recently, Chouihed et al. reported the result of PARADISE study, which consisted of not only patients with acute HF but also with inflammatory diseases. Results showed that high ePVS was significantly associated with in-hospital mortality in patients who visited emergency department (ED) for acute dyspnea [11]. In patients who visited the ED with fever, ePVS was independently associated with poor prognosis after adjusting for confounding factors [10].

In the present study, ePVS was significantly associated with in-hospital mortality and risk of RRT in critically ill patients with sepsis. A possible explanation for these results may be due to impairment of microcirculation during sepsis. As stated, microcirculatory dysfunction increases endothelial permeability, resulting to loss of protein-rich fluid from the vessel which leads to intravascular volume depletion and 
tissue edema. Accumulation of water in tissue leads to tissue hypoxia which is considered as a key factor in the development of organ dysfunction and death $[16,24]$.

The SAPS 3 and SOFA score are systematic scoring systems for sepsis patients created through largescale clinical studies and verified through various studies [1, 25]. In this study, ePVS has a similar prognostic value with SAPS3 or SOFA score in critically ill patients with sepsis. Although the in-hospital mortality AUC for ePVS (0.655) was lower than that for SAPS (0.768) or SOFA score (0.724), it was not significantly different with that for SAPS3 or SOFA score. Despite these similarities, the SAPS3 and SOFA scores were calculated using distinct, complicated formulas. Therefore, ePVS could be a simple tool to predict the prognosis of critically ill patients with sepsis.

To the best of our knowledge, this is the first study that evaluated the role of ePVS value in predicting the prognosis of critically ill patients with sepsis. However, the present study had some limitations. First, the size of this study was relatively small. Second, we did not evaluate the association between dynamic change in ePVS value and the prognosis of patients with sepsis. Although previous studies have suggested that variation of ePVS is associated with poor prognosis [8, 9], transfusion or bleeding commonly occurred after ICU admission in this study, so change in ePVS could not be evaluated. Third, correlation between the ePVS value and actual plasma volume status was not investigated. Although previous studies have reported that ePVS reflected plasma volume status, it would have been possible to provide more accurate information if the plasma volume status was measured by other methods. Therefore, additional studies need to be carried out in order to evaluate the correlation between ePVS and the actual PV value.

\section{Conclusions}

In summary, we found that ePVS, which can be performed simply at ICU admission, was significantly associated with mortality in patients with sepsis. Although further research is required to determine these clinical findings, ePVS may provide the prognostic granularity required for clinical use in critically ill patients with sepsis.

\section{Declarations}

\section{Ethics approval and consent to participate:}

This study was conducted in accordance with the relevant legislation and approved by the Ethics Committee of Seoul St. Mary's Hospital (KC18DESI0739) and complied with the Declaration of Helsinki and Good Clinical Practice Guidelines.

\section{Consent for publication:}

Informed consent was obtained from all participants included in the study. 
Availability of data and materials:

The data presented in this study are available on request from the corresponding author. The data are not publicly available due to the consent provided by participants on the use of confidential data.

\section{Conflict of interests:}

The authors declare no conflict of interest

\section{Funding:}

None

\section{Authors' contributions:}

Conceptualization, K.H.K. and J.L.; methodology, J.L. and S.C.K; formal analysis, K.H.K. and J.L.; data curation, J.H.J., K.H.K. and J.L.; writing-original draft preparation, K.H.K. and J.L.; writing-review and editing, S.C.K. and J.L.; visualization, K.H.K. and J.L.; supervision, S.C.K. and J.L.; project administration, S.C.K. and J.L. All authors have read and agreed to the published version of the manuscript.

\section{Acknowledgements:}

Not applicable

\section{Abbreviations}

AUC Area under curve

CBC Complete blood count

$\mathrm{Cl}$ Confidence interval

ED Emergency department

ePVS Estimated plasma volume status

HF Heart failure

ICU Intensive care unit

IQR interquartile ranges

MV Mechanical ventilation

OR Odds ratio

PPV Pulse pressure variation 
ROC Receiver operating curve

RRT Renal replacement therapy

SAPS3 Simplified Acute Physiology Score 3

SOFA Sequential Organ Failure Assessment

SSV Stroke volume variation

\section{References}

1. Singer M, Deutschman CS, Seymour CW, Shankar-Hari M, Annane D, Bauer M, Bellomo R, Bernard GR, Chiche JD, Coopersmith CM, et al: The Third International Consensus Definitions for Sepsis and Septic Shock (Sepsis-3). JAMA 2016, 315(8):801-810.

2. Ince C, Mayeux PR, Nguyen T, Gomez H, Kellum JA, Ospina-Tascon GA, Hernandez G, Murray P, De Backer D, Workgroup AX. The Endothelium in Sepsis. Shock. 2016;45(3):259-70.

3. Hotchkiss RS, Moldawer LL, Opal SM, Reinhart K, Turnbull IR, Vincent JL. Sepsis and septic shock. Nat Rev Dis Primers. 2016;2:16045.

4. Marik PE, Cavallazzi R, Vasu T, Hirani A. Dynamic changes in arterial waveform derived variables and fluid responsiveness in mechanically ventilated patients: a systematic review of the literature. Crit Care Med. 2009;37(9):2642-7.

5. De Backer D, Heenen S, Piagnerelli M, Koch M, Vincent JL. Pulse pressure variations to predict fluid responsiveness: influence of tidal volume. Intensive Care Med. 2005;31(4):517-23.

6. Miller WL. Fluid Volume Overload and Congestion in Heart Failure: Time to Reconsider Pathophysiology and How Volume Is Assessed. Circ Heart Fail. 2016;9(8):e002922.

7. Duarte K, Monnez JM, Albuisson E, Pitt B, Zannad F, Rossignol P. Prognostic Value of Estimated Plasma Volume in Heart Failure. JACC Heart Fail. 2015;3(11):886-93.

8. Kobayashi M, Rossignol P, Ferreira JP, Aragao I, Paku Y, Iwasaki Y, Watanabe M, Fudim M, Duarte K, Zannad F, et al. Prognostic value of estimated plasma volume in acute heart failure in three cohort studies. Clin Res Cardiol. 2019;108(5):549-61.

9. Huang CY, Lin TT, Wu YF, Chiang FT, Wu CK. Long-term Prognostic Value of Estimated Plasma Volume in Heart Failure with Preserved Ejection Fraction. Sci Rep. 2019;9(1):14369.

10. Turcato G, Zaboli A, Ciccariello L, Pfeifer N. Estimated plasma volume status (ePVS) could be an easy-to-use clinical tool to determine the risk of sepsis or death in patients with fever. J Crit Care. 2020;58:106-12.

11. Chouihed T, Rossignol P, Bassand A, Duarte K, Kobayashi M, Jaeger D, Sadoune S, Buessler A, Nace $L$, Giacomin G, et al. Diagnostic and prognostic value of plasma volume status at emergency department admission in dyspneic patients: results from the PARADISE cohort. Clin Res Cardiol. 2019;108(5):563-73. 
12. Charlson ME, Pompei P, Ales KL, MacKenzie CR. A new method of classifying prognostic comorbidity in longitudinal studies: development and validation. J Chronic Dis. 1987;40(5):373-83.

13. Rhodes A, Evans LE, Alhazzani W, Levy MM, Antonelli M, Ferrer R, Kumar A, Sevransky JE, Sprung CL, Nunnally ME, et al. Surviving Sepsis Campaign: International Guidelines for Management of Sepsis and Septic Shock: 2016. Intensive Care Med. 2017;43(3):304-77.

14. Osman D, Ridel C, Ray P, Monnet X, Anguel N, Richard C, Teboul JL. Cardiac filling pressures are not appropriate to predict hemodynamic response to volume challenge. Crit Care Med. 2007;35(1):64-8.

15. Boyd JH, Forbes J, Nakada TA, Walley KR, Russell JA. Fluid resuscitation in septic shock: a positive fluid balance and elevated central venous pressure are associated with increased mortality. Crit Care Med. 2011;39(2):259-65.

16. Miranda M, Balarini M, Caixeta D, Bouskela E. Microcirculatory dysfunction in sepsis: pathophysiology, clinical monitoring, and potential therapies. Am J Physiol Heart Circ Physiol. 2016;311(1):H24-35.

17. Cohen J. The immunopathogenesis of sepsis. Nature. 2002;420(6917):885-91.

18. Woodcock TE, Woodcock TM. Revised Starling equation and the glycocalyx model of transvascular fluid exchange: an improved paradigm for prescribing intravenous fluid therapy. $\mathrm{Br} \mathrm{J}$ Anaesth. 2012;108(3):384-94.

19. Chelazzi C, Villa G, Mancinelli P, De Gaudio AR, Adembri C. Glycocalyx and sepsis-induced alterations in vascular permeability. Crit Care. 2015;19:26.

20. Steppan J, Hofer S, Funke B, Brenner T, Henrich M, Martin E, Weitz J, Hofmann U, Weigand MA. Sepsis and major abdominal surgery lead to flaking of the endothelial glycocalix. J Surg Res. 2011;165(1):136-41.

21. Ince C. The microcirculation is the motor of sepsis. Crit Care. 2005;9(Suppl 4):13-9.

22. Bateman RM, Sharpe MD, Jagger JE, Ellis CG. Sepsis impairs microvascular autoregulation and delays capillary response within hypoxic capillaries. Crit Care. 2015;19:389.

23. Hippensteel JA, Uchimido R, Tyler PD, Burke RC, Han X, Zhang F, McMurtry SA, Colbert JF, Lindsell CJ, Angus DC, et al. Intravenous fluid resuscitation is associated with septic endothelial glycocalyx degradation. Crit Care. 2019;23(1):259.

24. Koch T, Geiger S, Ragaller MJ. Monitoring of organ dysfunction in sepsis/systemic inflammatory response syndrome: novel strategies. J Am Soc Nephrol. 2001;12(Suppl 17):53-9.

25. Moreno RP, Metnitz PGH, Almeida E, Jordan B, Bauer P, Campos RA, lapichino G, Edbrooke D, Capuzzo M, Le Gall J-R, et al. SAPS 3-From evaluation of the patient to evaluation of the intensive care unit. Part 2: Development of a prognostic model for hospital mortality at ICU admission. Intensive care medicine. 2005;31(10):1345-55.

\section{Figures}




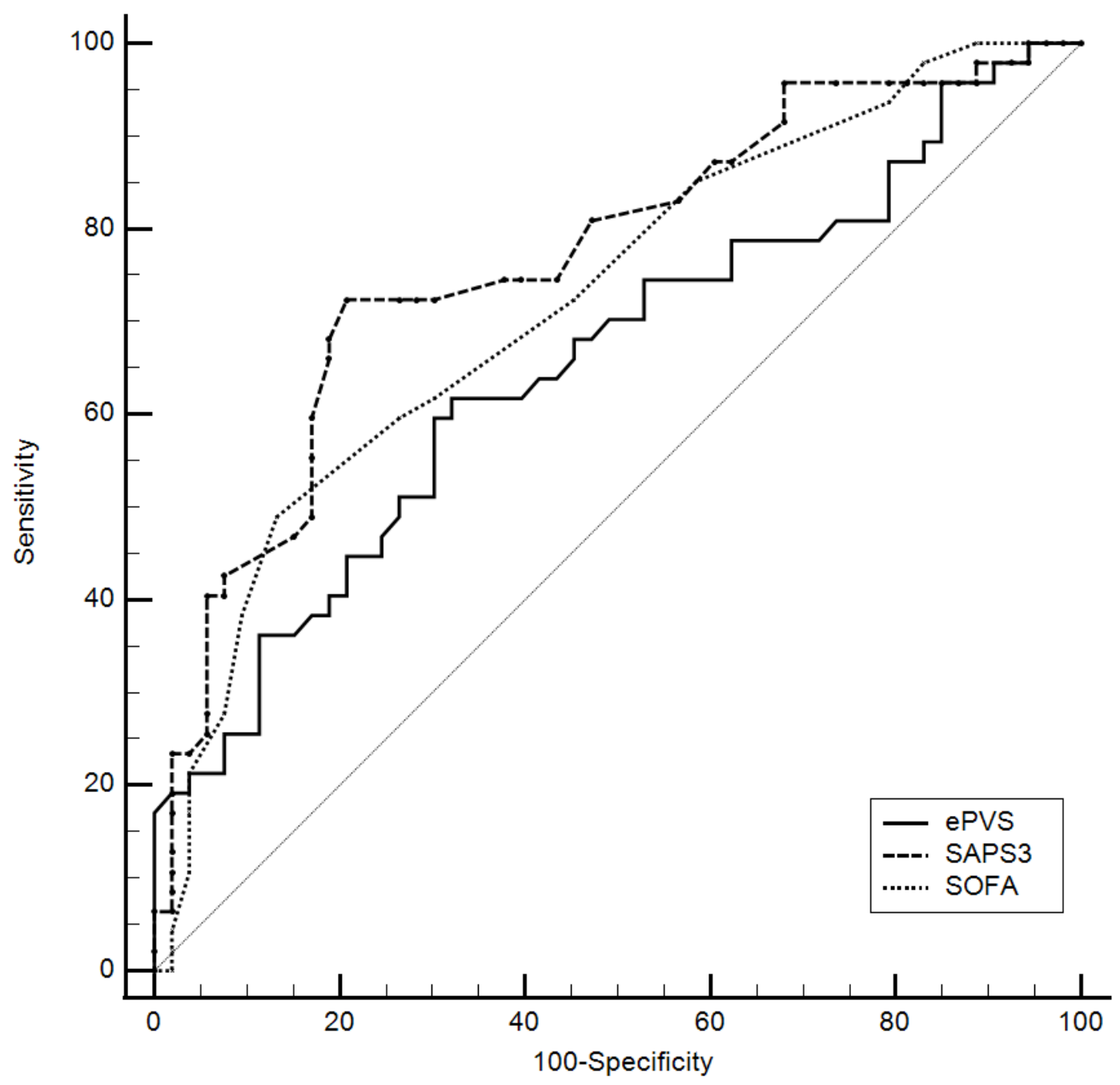

Figure 1

Comparison of receiver operating characteristics (ROC) curves of ePVS, SAPS3, and SOFA for predicting in-hospital mortality in critically ill patients with sepsis. 


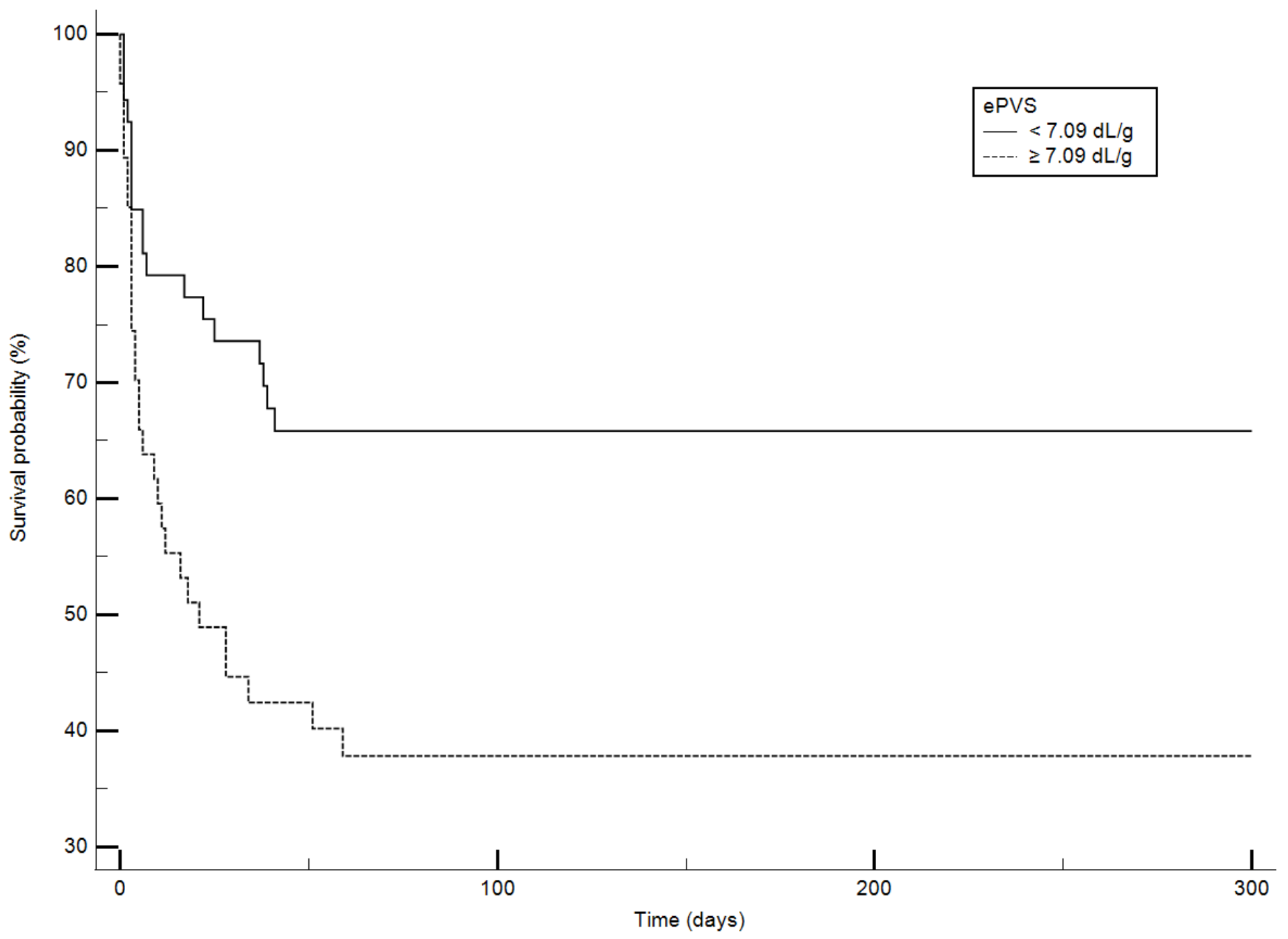

Figure 2

Kaplan-Meier survival analysis plot for in-hospital mortality divided between above and below cut-off ePVS value $(7.09 \mathrm{dL} / \mathrm{g})$. 